\title{
Improved Rotor-Position Estimation by Signal Injection in Brushless AC Motors, Accounting for Cross-Coupling Magnetic Saturation
}

\author{
Yi Li, Z. Q. Zhu, Fellow, IEEE, David Howe, Chris M. Bingham, Member, IEEE, and Dave A. Stone
}

\begin{abstract}
This paper presents an improved signal-injectionbased sensorless-control method for permanent-magnet brushless ac (BLAC) motors, accounting for the influence of cross-coupling magnetic saturation between the $d$ - and $q$-axes. The $d$ - and $q$-axis incremental self-inductances, the incremental mutual inductance between the $d$-axis and $q$-axis, and the cross-coupling factor are determined by finite-element analysis. An experimental method is proposed for measuring the cross-coupling factor which can be used directly in the sensorless-control scheme. Both measurements and predictions show that a significant improvement in the accuracy of the rotor-position estimation can be achieved under both dynamic and steady-state operation compared with that which is obtained with the conventional signal-injection method.
\end{abstract}

Index Terms-Brushless ac (BLAC) motor, cross-coupling effect, sensorless, signal injection.

\section{INTRODUCTION}

A CCURATE rotor-position information is an essential requirement for permanent-magnet (PM) brushless ac (BLAC) drives. Thus, either an encoder or a resolver is usually employed. However, this increases the cost and complexity and may compromise the reliability. Hence, there has been a significant development effort on sensorless techniques, which estimate the rotor position indirectly from the phase voltages and currents.

Various back-EMF-based rotor-position-estimation methods have been developed for PM BLAC motors [1]-[3], which all estimate the rotor position from the governing voltage equation, their difference being in the way that the rotor position and speed estimation are deduced. However, they require accurate stator-winding inductances and resistances, may be problematic at low speed, and cannot be used for starting.

Hence, the most popular sensorless-control method for starting and low-speed operation is based on injecting a highfrequency voltage signal into the phase windings and measuring

Paper 2008-EMC-206, presented at the 2007 Industry Applications Society Annual Meeting, New Orleans, LA, September 23-27, and approved for publication in the IEEE TRANSACTIONS ON INDUSTRY APPLICATIONS by the Electric Machines Committee of the IEEE Industry Applications Society. Manuscript submitted for review November 22, 2008 and released for publication March 26, 2009. First published July 14, 2009; current version published September 18, 2009.

The authors are with the Department of Electronic and Electrical Engineering, University of Sheffield, Sheffield, S1 3JD, U.K. (e-mail: Lijikang99@yahoo.com; Z.Q.Zhu@sheffield.ac.uk; D.Howe@sheffield.ac.uk; C.Bingham@sheffield.ac.uk; D.A.Stone@sheffield.ac.uk).

Digital Object Identifier 10.1109/TIA.2009.2027518 the resultant high-frequency current. Such a method was originally developed for induction motors and was subsequently extended to PM BLAC motors with saliency [4]-[6]. The identification of the initial rotor polarity, which was not reported in [4]-[6], was achieved in [7] and [8] by comparing the sine and cosine terms of the second harmonic component in the $d$-axis high-frequency current. In all the foregoing papers, the signal-injection technique was applied to BLAC motors, which have geometric rotor saliency. In [9], it was extended to a BLAC motor with a surface-mounted PM rotor by utilizing the saliency which resulted from magnetic saturation. In [5]-[9], the high-frequency signal was injected into the $d$-axis, which was aligned with the rotor. Alternatively, the high-frequency signals can also be injected into an $\alpha \beta$-axis [10], [11], which are fixed with the stator winding. Since the signals are injected into the $\alpha \beta$-axis rather than the estimated $d$-axis, the control strategy in [10] and [11] may be more stable than the other methods.

However, it was found experimentally [5] that the error in the estimated rotor position increased with the load current, although the problem was not specifically addressed. More recently, it has been shown in [12] and [13] that the rotor-position-estimation error was caused by $d q$-axis crosscoupling, i.e., $L_{d q h} \neq 0$ and was dependent on the machine design, although no measures were taken to reduce the error. In [10] and [11], the equivalent machine model was used as in [5], except that it was transformed from the $d q$-axis to the $\alpha \beta$-axis reference frame. When $L_{d q h} \neq 0$, it was described as the 'saliency offset' in $L_{\alpha h}, L_{\beta h}$, and $L_{\alpha \beta h}$. It is well known that the mutual inductance between the $d$ - and $q$-axes $\left(L_{d q h}\right)$ of a BLAC motor results from cross-coupling due to magnetic saturation, as shown in [14], by both measurement and finiteelement analysis. However, for simplicity, the influence of cross-coupling magnetic saturation is usually neglected in the electromagnetic modeling [15], [16], vector control [17], [18], and sensorless position control [5]-[9] of BLAC motors.

This paper improves the accuracy of the rotor-position estimation by accounting for the influence of cross-coupling magnetic saturation in the signal-injection-based sensorless method. Section II presents the underlying theory and analyzes the rotorposition-estimation error which results when the influence of cross-coupling is neglected. Section III proposes a simple way of accounting for the cross coupling based on data which can be obtained either by finite-element analysis or from measurements. Finally, predicted and measured results are compared in 
Section IV to validate the proposed improved signal-injection sensorless-control method.

\section{ANALYSIS OF ROTOR-POSITION-ESTIMATION ERROR CAused By CRoss Coupling}

When cross coupling between the $d$ - and $q$-axes is considered, the voltage equations of a BLAC motor, in the rotor $d q$-axis reference frame, are given by [14]

$\left[\begin{array}{c}v_{d} \\ v_{q}\end{array}\right]=\left[\begin{array}{cc}R_{s}+L_{d h} p & -\omega_{r} L_{q}+L_{d q h} p \\ \omega_{r} L_{d}+L_{q d h} p & R_{s}+L_{q h} p\end{array}\right]\left[\begin{array}{c}i_{d} \\ i_{q}\end{array}\right]+q\left[\begin{array}{c}0 \\ \omega_{r} \psi_{m}\end{array}\right]$

where $R_{s}$ is the stator-winding phase resistance and $\psi_{m}$ is the flux linkage per phase due to the PMs, $\omega_{r}$ is the angular rotational speed, and $p=d / d t . v_{d}, v_{q}$ and $i_{d}, i_{q}$ are the $d$ and $q$-axis voltages and currents, $L_{d}$ and $L_{q}$ are the apparent $d-q$ axis self-inductances, respectively, and $L_{d h}, L_{q h}, L_{d q h}$, and $L_{q d h}$ are the $d$ - and $q$-axis incremental self- and mutual inductances, defined by

$$
\left\{\begin{array}{l}
L_{d h}=\left[\psi_{d}\left(i_{d}+\Delta i_{d}, i_{q}, \Phi_{m}\right)-\psi_{d}\left(i_{d}, i_{q}, \Phi_{m}\right)\right] / \Delta i_{d} \\
L_{q h}=\left[\psi_{q}\left(i_{d}, i_{q}+\Delta i_{q}, \Phi_{m}\right)-\psi_{q}\left(i_{d}, i_{q}, \Phi_{m}\right)\right] / \Delta i_{q} \\
L_{d q h}=\left[\psi_{d}\left(i_{d}, i_{q}+\Delta i_{q}, \Phi_{m}\right)-\psi_{d}\left(i_{d}, i_{q}, \Phi_{m}\right)\right] / \Delta i_{q} \\
L_{q d h}=\left[\psi_{q}\left(i_{d}+\Delta i_{d}, i_{q}, \Phi_{m}\right)-\psi_{q}\left(i_{d}, i_{q}, \Phi_{m}\right)\right] / \Delta i_{d}
\end{array}\right.
$$

where $\Phi_{m}$ is the PM flux.

Due to magnetic saturation, $L_{d h}, L_{q h}, L_{d q h}$, and $L_{q d h}$ vary with both $i_{d}$ and $i_{q}$. By way of example, Fig. 1 shows the finite-element calculated incremental-winding inductances for the interior-magnet BLAC motor whose parameters are given in Table I. As can be seen, $L_{d h}$ and $L_{q h}$ reduce as $i_{d}$ and $i_{q}$ are increased.

When only the high-frequency signal-injection components are considered, (1) can be approximated by

$$
\left[\begin{array}{c}
v_{d h} \\
v_{q h}
\end{array}\right]=\left[\begin{array}{cc}
L_{d h} & L_{d q h} \\
L_{d q h} & L_{q h}
\end{array}\right] p\left[\begin{array}{c}
i_{d h} \\
i_{q h}
\end{array}\right] .
$$

Equation (3) can be transformed from the rotor-position reference frame $\left(\theta_{r}\right)$ to the estimated rotor-position reference frame $\left(\theta_{r}^{e}\right)$ by the following transformation matrix $T(\Delta \theta)$, viz.,

$$
T(\Delta \theta)=\left[\begin{array}{cc}
\cos (\Delta \theta) & \sin (\Delta \theta) \\
-\sin (\Delta \theta) & \cos (\Delta \theta)
\end{array}\right]
$$

where $\Delta \theta$ is the error in the estimated rotor position, i.e., $\Delta \theta=$ $\theta_{r}^{e}-\theta_{r}$ is the difference between the estimated rotor position and the actual rotor position. Hence, we have (5), shown at the bottom of the next page, where

$$
\begin{aligned}
& \left\{\begin{array}{l}
L_{\mathrm{avg}}=\left(L_{q h}+L_{d h}\right) / 2 \\
L_{\mathrm{dif}}=\left(L_{q h}-L_{d h}\right) / 2
\end{array}\right. \\
& \left\{\begin{array}{l}
\theta_{m}=\arctan \left(L_{d q h} / L_{\mathrm{dif}}\right)=\arctan \left[2 L_{d q h} /\left(L_{q h}-L_{d h}\right)\right] \\
\widehat{L}_{\mathrm{dif}}=\sqrt{L_{\mathrm{dif}}^{2}+L_{d q h}^{2}} .
\end{array}\right.
\end{aligned}
$$

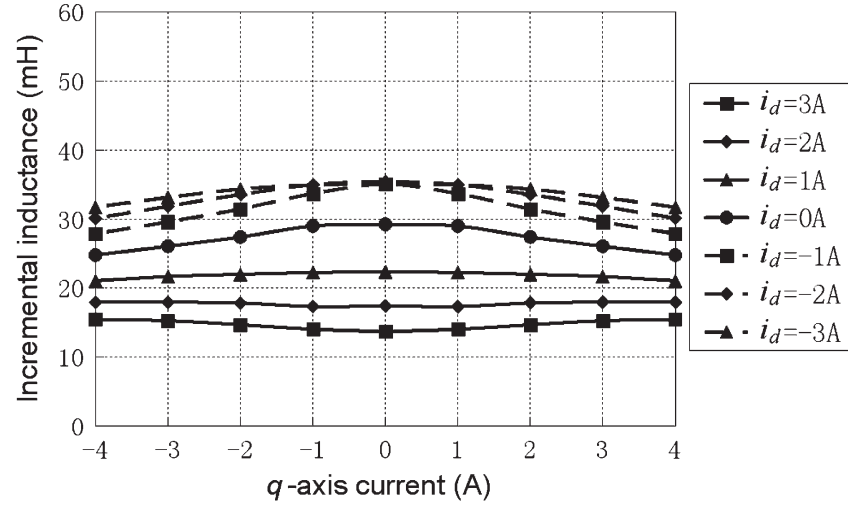

(a)

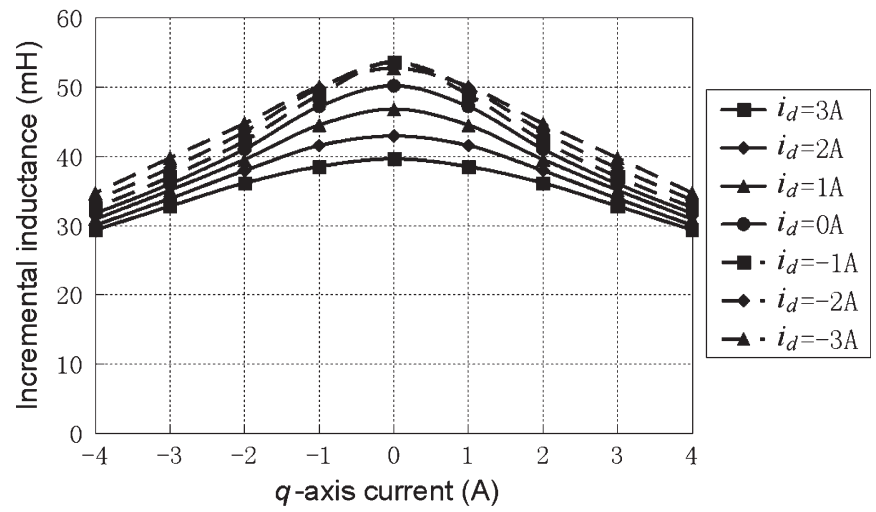

(b)

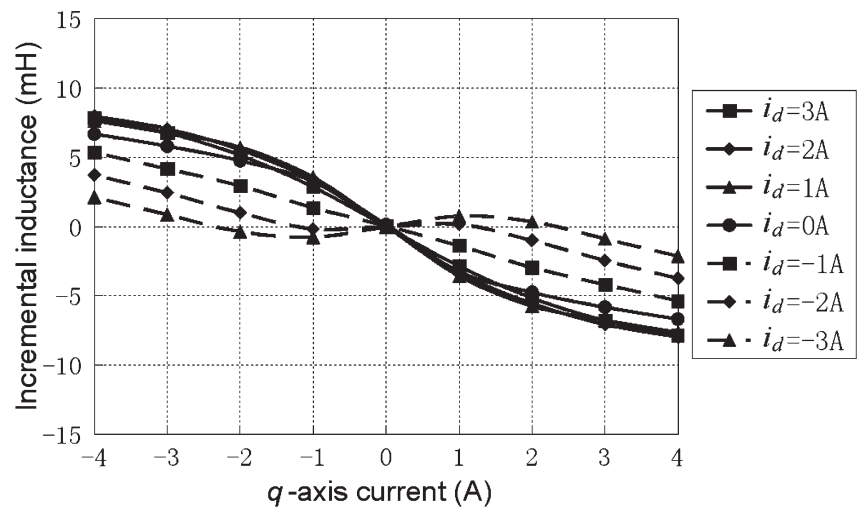

(c)

Fig. 1. Finite-element predicted incremental self- and mutual inductances. (a) $d$-axis incremental self-inductance $L_{d h}$. (b) $q$-axis incremental selfinductance $L_{q h}$. (c) $d q$-axis incremental mutual inductances, $L_{d q h}$ and $L_{q d h}$.

TABLE I

PARAMETERS OF A BLAC MOTOR

\begin{tabular}{|l|l|}
\hline Rated voltage (peak) & $158 \mathrm{~V}$ \\
\hline Rated current (peak) & $4.0 \mathrm{~A}$ \\
\hline Rated power & $0.6 \mathrm{~kW}$ \\
\hline Rated speed & $1000 \mathrm{rpm}$ \\
\hline Rated torque & $4.0 \mathrm{Nm}$ \\
\hline Pole number & 6 \\
\hline Stator resistance $\left(R_{s}\right)$ & $6.0 \Omega$ \\
\hline
\end{tabular}

Since the high-frequency voltage signal, $v_{\text {sig }}=$ $V_{\text {inj }} \sin \left(2 \pi f_{\mathrm{HF}} t\right)$, is applied to the $d$-axis, (5) becomes (8), as shown at the bottom of the next page. 
The high-frequency $d$ - and $q$-axis currents in the estimated rotor-position reference frame are obtained as

$$
\left\{\begin{array}{l}
i_{d h}^{e}=\frac{v_{s i g}}{p\left(L_{\mathrm{avg}}^{2}-\widehat{L}_{\mathrm{dif}}^{2}\right)}\left[L_{\mathrm{avg}}+\widehat{L}_{\mathrm{dif}} \cos \left(2 \Delta \theta+\theta_{m}\right)\right] \\
i_{q h}^{e}=-\frac{v_{\text {sig }}}{p\left(L_{\mathrm{avg}}^{2}-\widehat{L}_{\mathrm{dif}}^{2}\right)} \widehat{L}_{\mathrm{dif}} \sin \left(2 \Delta \theta+\theta_{m}\right) .
\end{array}\right.
$$

In the conventional signal-injection-based sensorless method, cross coupling between the $d$ - and $q$-axes is neglected, and the high-frequency component in the $q$-axis current is assumed to be proportional to the estimation error in rotor position [9]. Therefore, $i_{q h}^{e}$ is forced to zero in order to make the estimation error zero in the conventional method, i.e.,

$$
i_{q h}^{e}=-\frac{v_{\mathrm{sig}}}{p\left(L_{\mathrm{avg}}^{2}-\widehat{L}_{\mathrm{dif}}^{2}\right)} \widehat{L}_{\mathrm{dif}} \sin \left(2 \Delta \theta+\theta_{m}\right)=0 .
$$

In this case, an error exists in the estimated rotor position as a result of the incremental mutual inductance between the $d$ - and $q$-axes $L_{d q h}$. The error is given by

$$
\Delta \theta=\theta_{r}^{e}-\theta_{r}=-\theta_{m} / 2 \approx \frac{1}{2} \arctan \left(\frac{2 L_{d q h}}{L_{d h}-L_{q h}}\right)
$$

where $\theta_{r}^{e}$ and $\theta_{r}$ are the estimated and actual rotor positions, respectively.

Clearly, the rotor-position error will be zero only when $L_{d q h}=0$, while the stronger the cross coupling between the $d$ and $q$-axes, the larger will be the error, as will be shown later.

\section{IMPROVED SignAL-INJECTION SENSORLESS Method}

In [19], the error in the estimated rotor position due to the neglect of the incremental mutual inductance between the $d$ - and $q$-axes $L_{d q h}$ was analyzed by finite-element analysis and experimentally, and a method was proposed to directly compensate for the error by employing (11) based on either the finite-element predicted incremental inductances, $L_{d h}, L_{q h}$, $L_{d q h}$, which are shown in Fig. 1, or using premeasured errors. However, this improved method was still essentially based on the conventional sensorless method which forces the high- frequency component in the $q$-axis current to be zero, together with the error compensation.

In this section, an alternative method of improving the signalinjection-based sensorless method is proposed to eliminate the potentially large error in the estimated rotor position caused by the influence of $d$ - and $q$-axis cross coupling, i.e., $L_{d q h} \neq 0$. Rather than forcing the high-frequency component in the $q$-axis current to be zero, as in the conventional sensorless method, an optimal relationship between the high-frequency components of the $d$ - and $q$-axis currents is established from the analysis presented in Section II.

When the rotor-position-estimation error $\Delta \theta$ is sufficiently small, (9) can be approximated by

$$
\begin{aligned}
& i_{d h}^{e} \approx \frac{v_{\mathrm{sig}}}{p\left(L_{\mathrm{avg}}^{2}-\widehat{L}_{\mathrm{dif}}^{2}\right)}\left(L_{q h}-2 L_{d q h} \cdot \Delta \theta\right) \\
& i_{q h}^{e} \approx \frac{v_{\mathrm{sig}}}{p\left(L_{\mathrm{avg}}^{2}-\widehat{L}_{\mathrm{dif}}^{2}\right)}\left(-L_{d q h}-2 L_{\mathrm{dif}} \cdot \Delta \theta\right) .
\end{aligned}
$$

Both sides of (12a) are multiplied by $L_{d q h} / L_{q h}$ and added to (12b) to give

$$
i_{q h}^{e}+\lambda i_{d h}^{e}=\frac{v_{\mathrm{sig}}}{p\left(L_{\mathrm{avg}}^{2}-\widehat{L}_{\mathrm{dif}}^{2}\right)}\left(-2 L_{\mathrm{dif}}-2 \lambda L_{d q h}\right) \cdot \Delta \theta
$$

where $\lambda=L_{d q h} / L_{q h}$ is defined as the coupling factor, which can either be calculated from a knowledge of the machine parameters or deduced experimentally, as shown next.

Thus, when the effect of cross coupling is considered, the rotor-position-estimation error $\Delta \theta$ can be calculated as

$$
\Delta \theta=\frac{\left(L_{\mathrm{avg}}^{2}-\widehat{L}_{\mathrm{dif}}^{2}\right) p\left(i_{q h}^{e}+\lambda i_{d h}^{e}\right)}{-2 v_{\mathrm{sig}}\left(L_{\mathrm{dif}}+\lambda L_{d q h}\right)}=\hat{k}_{\mathrm{HF}}^{\Delta \theta} \cdot\left(i_{q h}^{e}+\lambda i_{d h}^{e}\right)
$$

where $\hat{k}_{\mathrm{HF}}^{\Delta \theta}=\left(L_{\mathrm{avg}}^{2}-\widehat{L}_{\mathrm{dif}}^{2}\right) p /-2 v_{\mathrm{sig}}\left(L_{\mathrm{dif}}+\lambda L_{d q h}\right)$ is a coefficient which enables the rotor-position-estimation error to be determined from $\left(i_{q h}^{e}+\lambda i_{d h}^{e}\right)$. In (13) and (14), it is noted that the rotor-position-estimation error $\Delta \theta$ is proportional to

$$
\begin{aligned}
{\left[\begin{array}{c}
v_{d h}^{e} \\
v_{q h}^{e}
\end{array}\right] } & =T(\Delta \theta)\left[\begin{array}{c}
v_{d h} \\
v_{q h}
\end{array}\right]=T(\Delta \theta)\left[\begin{array}{cc}
L_{d h} & L_{d q h} \\
L_{d q h} & L_{q h}
\end{array}\right] T^{-1}(\Delta \theta) \cdot p\left[\begin{array}{c}
i_{d h}^{e} \\
i_{q h}^{e}
\end{array}\right] \\
& =\left[\begin{array}{cc}
L_{\mathrm{avg}}-\hat{L}_{\mathrm{dif}} \cos \left(2 \Delta \theta+\theta_{m}\right) & \widehat{L}_{\mathrm{dif}} \sin \left(2 \Delta \theta+\theta_{m}\right) \\
\widehat{L}_{\mathrm{dif}} \sin \left(2 \Delta \theta+\theta_{m}\right) & L_{\mathrm{avg}}+\widehat{L}_{\mathrm{dif}} \cos \left(2 \Delta \theta+\theta_{m}\right)
\end{array}\right] p\left[\begin{array}{c}
i_{d h}^{e} \\
i_{q h}^{e}
\end{array}\right]
\end{aligned}
$$

$$
\left[\begin{array}{c}
v_{\text {sig }} \\
0
\end{array}\right]=\left[\begin{array}{cc}
L_{\mathrm{avg}}-\widehat{L}_{\mathrm{dif}} \cos \left(2 \Delta \theta+\theta_{m}\right) & \widehat{L}_{\mathrm{dif}} \sin \left(2 \Delta \theta+\theta_{m}\right) \\
\widehat{L}_{\mathrm{dif}} \sin \left(2 \Delta \theta+\theta_{m}\right) & L_{\mathrm{avg}}+\widehat{L}_{\mathrm{dif}} \cos \left(2 \Delta \theta+\theta_{m}\right)
\end{array}\right] p\left[\begin{array}{c}
i_{d h}^{e} \\
i_{q h}^{e}
\end{array}\right]
$$




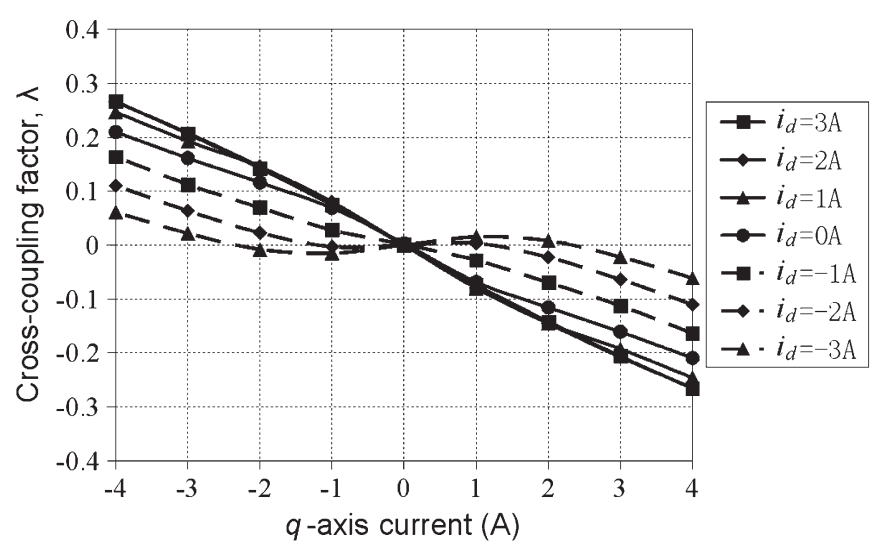

(a)

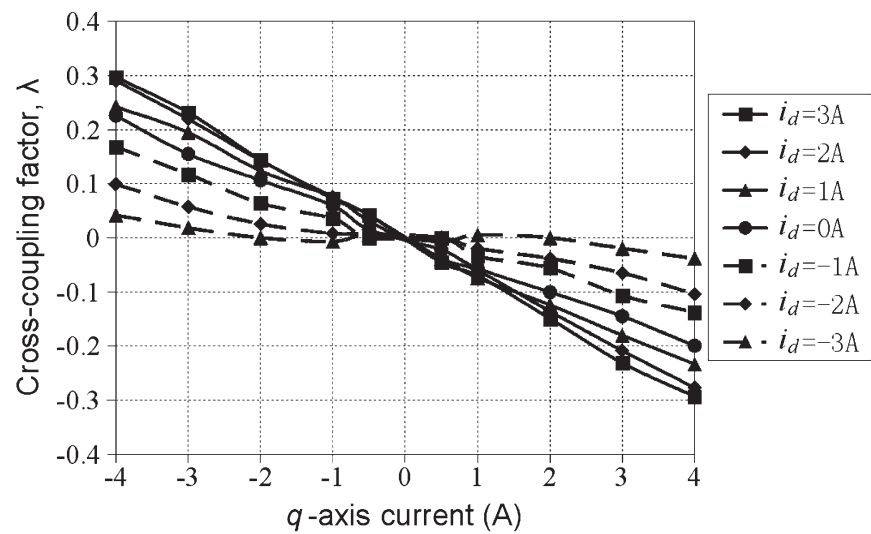

(b)

Fig. 2. Comparison of predicted and measured coupling factor $(\lambda)$. (a) Finiteelement calculated. (b) Measured.

$\left(i_{q h}^{e}+\lambda i_{d h}^{e}\right)$. Therefore, by forcing $\left(i_{q h}^{e}+\lambda i_{d h}^{e}\right)$ to be zero, $\Delta \theta$ can be controlled to be zero. Hence, the determination of $\lambda$ is the key to realizing the proposed improved sensorless-control method.

By definition, the value of the coupling factor $\lambda$ for various combinations of $d$ - and $q$-axis currents can be predicted from the finite-element calculated values of $L_{q h}$ and $L_{d q h}$ [Fig. 1(b) and (c)], as shown in Fig. 2(a). Clearly, the accuracy of $\lambda$, and, consequently, the accuracy of the rotor-position estimation, depends on the ratio of $L_{d q h} / L_{q h}$, both $L_{d q h}$ and $L_{q h}$ varying with $d$ - and $q$-axis currents.

The coupling factor $\lambda$ can also be measured directly by driving the BLAC motor by the actual rotor position with an encoder, for example. In this way, by injecting the highfrequency signal $v_{\text {sig }}$ on the actual $d$-axis, (3) becomes

$$
\left[\begin{array}{c}
v_{\text {sig }} \\
0
\end{array}\right]=\left[\begin{array}{cc}
L_{d h} & L_{d q h} \\
L_{d q h} & L_{q h}
\end{array}\right] p\left[\begin{array}{c}
i_{d h} \\
i_{q h}
\end{array}\right] .
$$

The corresponding high-frequency $d$ - and $q$-axis current components are obtained from (15) as

$$
\begin{aligned}
& i_{d h}=\frac{v_{\mathrm{sig}}}{p\left(L_{\mathrm{avg}}^{2}-\widehat{L}_{\mathrm{dif}}^{2}\right)} L_{q h} \\
& i_{q h}=-\frac{v_{\mathrm{sig}}}{p\left(L_{\mathrm{avg}}^{2}-\widehat{L}_{\mathrm{dif}}^{2}\right)} L_{d q h} .
\end{aligned}
$$

Therefore, it can be seen, from (16a) and (16b), that the coupling factor $\lambda$ can be obtained from the measured values of $i_{d h}$ and $i_{q h}$, as

$$
\lambda=\frac{L_{d q h}}{L_{q h}}=-\frac{i_{q h}}{i_{d h}} .
$$

The measured coupling factor $\lambda$ for various $d$ - and $q$-axis currents are shown in Fig. 2(b). It can be seen that there is an excellent agreement between the finite-element predicted and measured coupling factors.

While the value of $\lambda$ to be used in the improved signalinjection-based sensorless method can be determined by interpolating the data shown in Fig. 2, in order to implement the method on a DSP, the calculation of $\lambda$ is simplified by representing the data in Fig. 2 by the following simple function, viz.:

$$
\lambda= \begin{cases}-k_{1} \cdot i_{q}^{e}, & i_{d}^{e} \geq 0 \\ -\left(k_{1}+k_{2} \cdot i_{d}^{e}\right) \cdot i_{q}^{e}, & i_{d}^{e}<0\end{cases}
$$

where $k_{1}$ and $k_{2}$ are coefficients. For the BLAC motor under consideration, $k_{1}=0.05 \mathrm{~A}^{-1}$ and $k_{2}=0.011 \mathrm{~A}^{-2}$ from the finite-element calculated value of $\lambda$ [Fig. 2(a)], and $k_{1}=$ $0.06 \mathrm{~A}^{-1}, k_{2}=0.011 \mathrm{~A}^{-2}$ from the measured values of $\lambda$ [Fig. 2(b)].

In practice, multipliers and low-pass filters are used to obtain the high-frequency $d$ - and $q$-axis current components, $i_{d h}^{e}$ and $i_{q h}^{e}$ [9], for use in (14) to calculate the error $\Delta \theta$ in the estimated rotor position. $\Delta \theta$ is then input to a proportional-integral regulator to correct the estimated rotor position $\theta_{r}^{e}$ and speed $\omega_{r}^{e}$. Hence, since the cross coupling is now accounted for in the rotor-position estimation, the accuracy is improved significantly.

Clearly, when the cross coupling is sufficiently small compared with $L_{q h}$, i.e., $L_{d q h} \approx 0$ and, hence, $\lambda \approx 0$, the proposed sensorless-control strategy results in $i_{q h}^{e}=0$ and is identical to the conventional signal-injection-based sensorless method.

\section{Simulated And Measured Results}

In order to demonstrate the utility of the improved signalinjection method, both simulated results and measurements have been obtained for the BLAC motor, whose parameters are given in Table I.

The sensorless controller was implemented on a TMS320C31 DSP, while a 1024 pulse/r encoder was used to measure the actual rotor position $\theta_{r}$. The A/D sampling and pulsewidth-modulation switching frequency were both $5 \mathrm{kHz}$, while the injected sinusoidal signal was $35 \mathrm{~V}, 330 \mathrm{~Hz}$. The control-loop cycle was $200 \mu \mathrm{s}$, and the measured coupling factor $\lambda$, shown in Fig. 2(b) and represented by (18), was used (Fig. 3), for which a flowchart is shown in Fig. 4.

Fig. 5 shows the estimated and actual rotor position when the demanded rotor speed is changed from -10 to $+10 \mathrm{~Hz}$, i.e., -200 to 200 r/min. As will be evident from Fig. 5(a), when the conventional signal-injection-based sensorless method is employed, good agreement is only achieved when the current is relatively small, the error in the estimated rotor position 


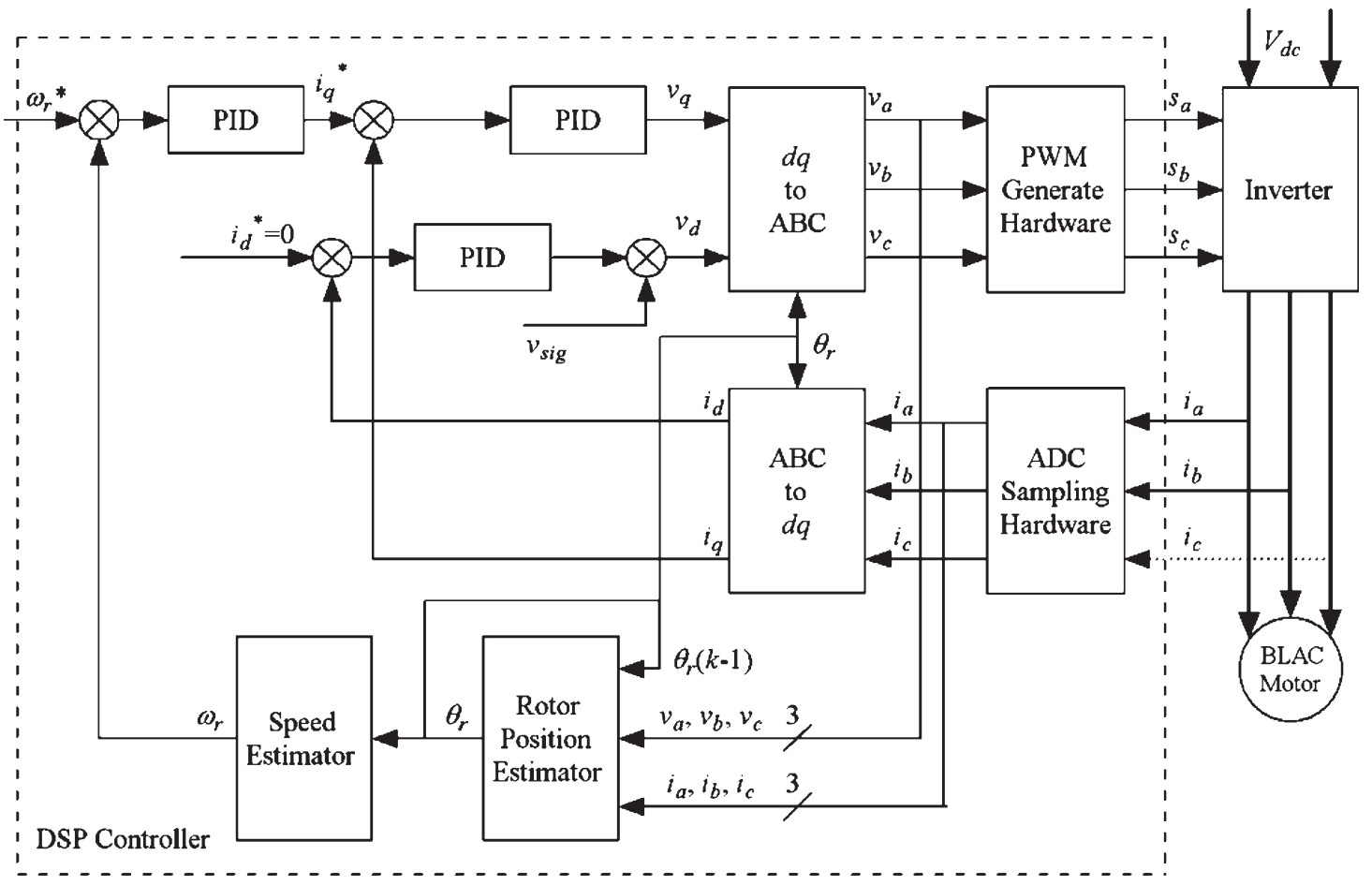

Fig. 3. Sensorless BLAC motor drive system.

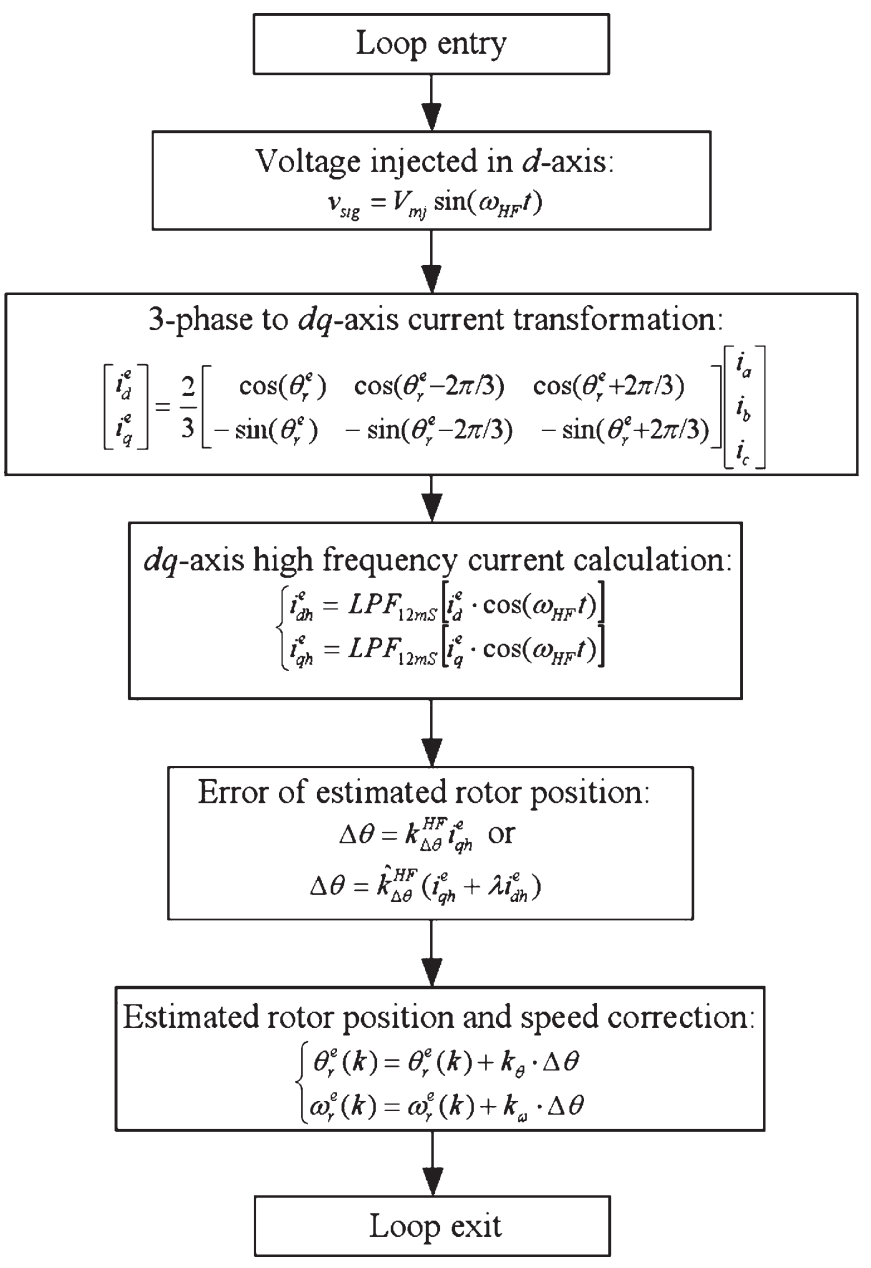

Fig. 4. Flowchart of signal-injection-based position estimation.

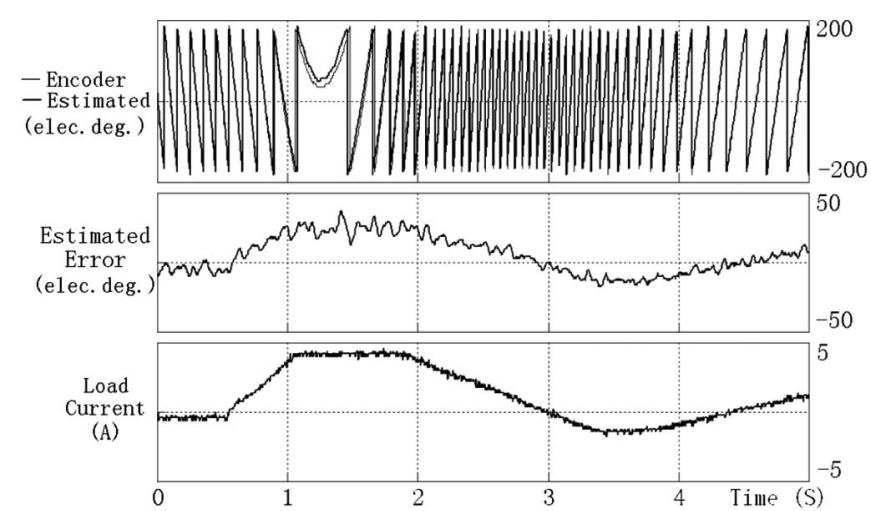

(a)

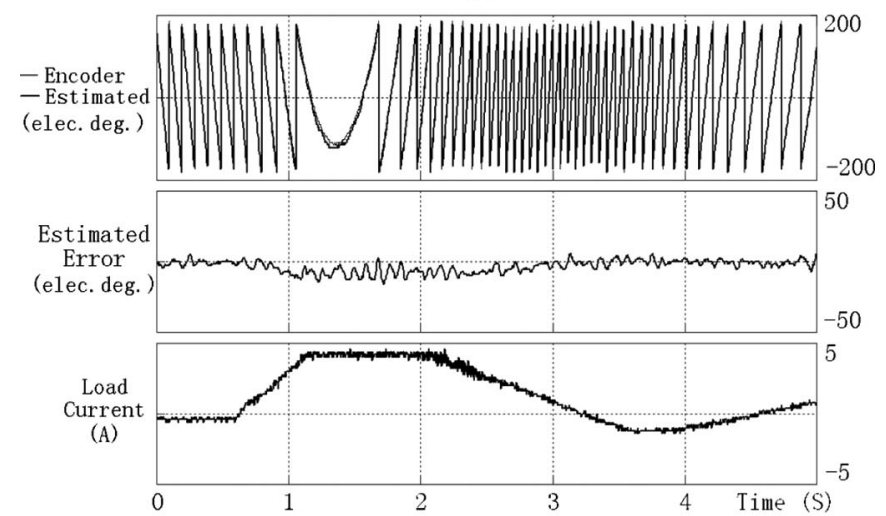

(b)

Fig. 5. Measured step-speed responses (speed command: $\pm 10 \mathrm{~Hz}$ ). (a) Conventional signal-injection method. (b) Improved signal-injection method.

increasing significantly with the current, e.g., the error is $25^{\circ}$ electrical when $i_{q}=4 \mathrm{~A}$. However, when the improved signal-injection method is employed, this error reduces to 


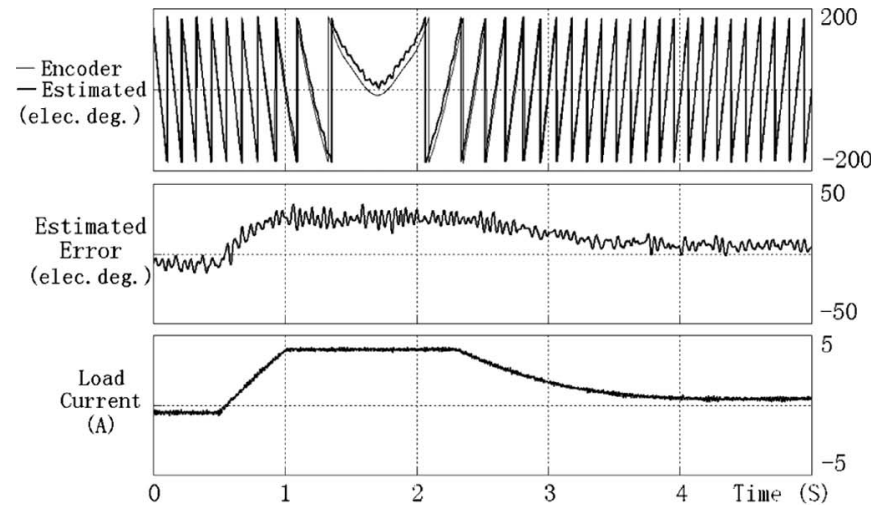

(a)
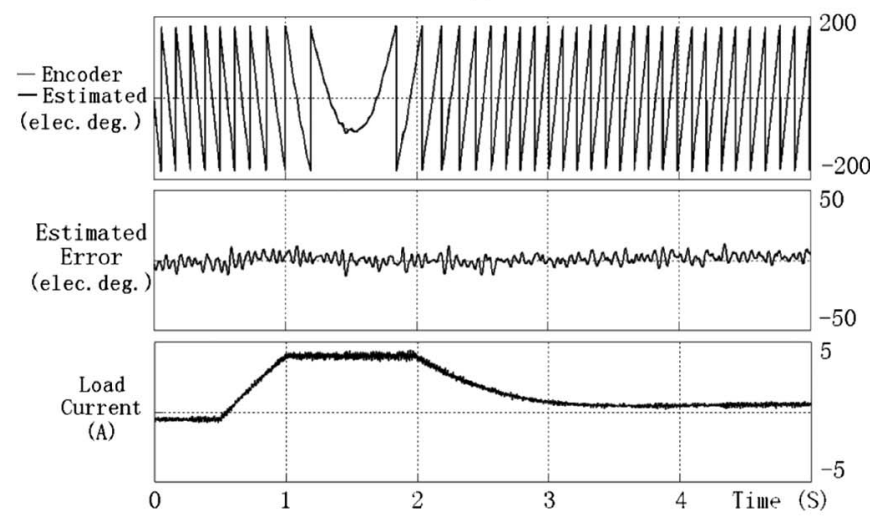

(b)

Fig. 6. Simulated step-speed responses (speed command: $\pm 10 \mathrm{~Hz}$ ). (a) Conventional signal-injection method. (b) Improved signal-injection method.

$5^{\circ}$ (electrical) Fig. 5(b). This improvement is also confirmed by the simulated results shown in Fig. 6.

Fig. 7 shows the measured steady-state error in the estimated rotor position for various $d$ - and $q$-axis currents, $i_{d}^{e}$ and $i_{q}^{e}$, when the estimated rotor position is used for position feedback. With the conventional signal-injection method Fig. 7(a), the error increases as both the absolute value of $i_{q}$ and the positive value of $i_{d}$ are increased, due to increased saturation and the consequent increase in the influence of cross coupling. For example, the maximum error in full $d q$-axis current ranges, as shown in Fig. 7(a), to $45.0^{\circ}$ electrical. From Fig. 7(b), when the improved signal-injection method is employed, the maximum error is reduced to $6.1^{\circ}$ electrical. This improvement is confirmed by the simulated results shown in Fig. 8, for which the corresponding maximum errors in the estimated rotor position are $37.4^{\circ}$ electrical and $2.7^{\circ}$ electrical, respectively.

\section{Conclusion}

Cross-coupling magnetic saturation between the $d$ - and $q$-axes of a PM BLAC motor can significantly influence the accuracy of rotor-position estimation by signal-injection-based methods. This paper has presented an improved signal-injection method which accounts for the cross-coupling effect. The $d$ and $q$-axis incremental self-inductances and the incremental mutual inductance between the $d$ - and $q$-axes have been calculated by finite-element analysis and a cross-coupling factor determined. An experimental method has been proposed to

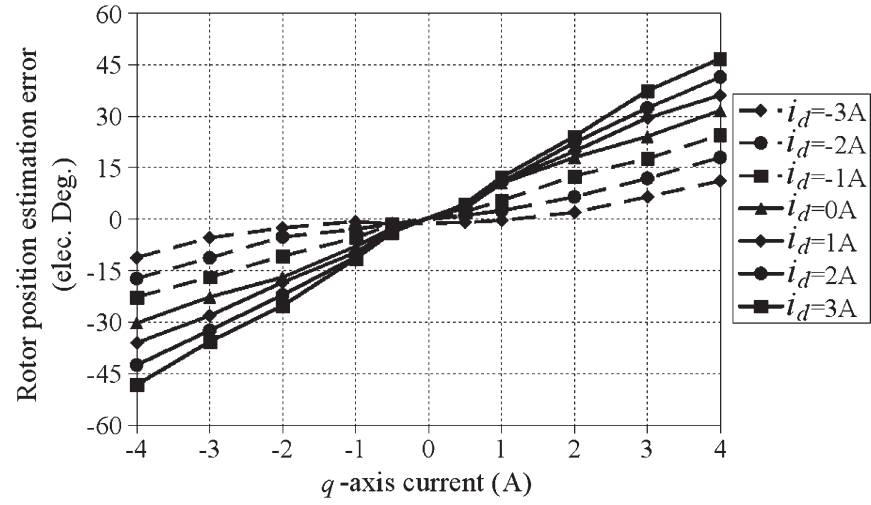

(a)

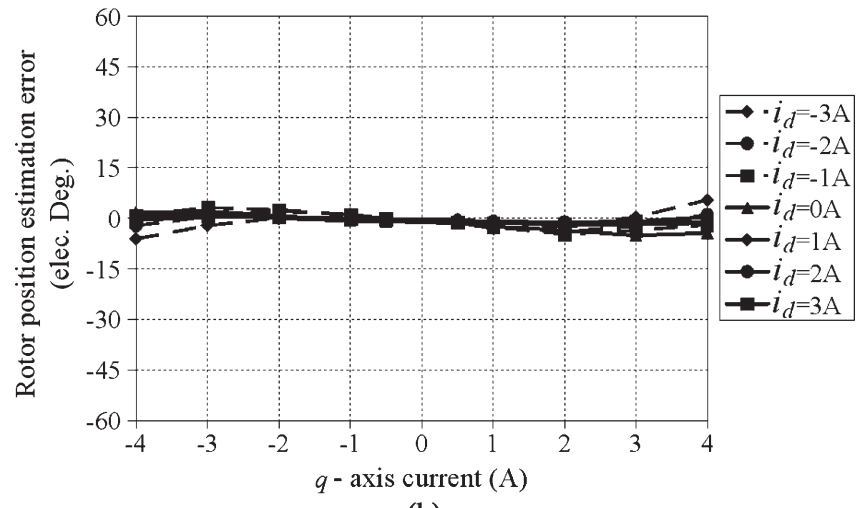

(b)

Fig. 7. Measured rotor-position-estimation error. (a) Conventional method, $\operatorname{MAX}\left(\theta_{r}^{e}-\theta_{r}\right)=45.0^{\circ}$. (b) Improved method, $\operatorname{MAX}\left(\theta_{r}^{e}-\theta_{r}\right)=6.1^{\circ}$.

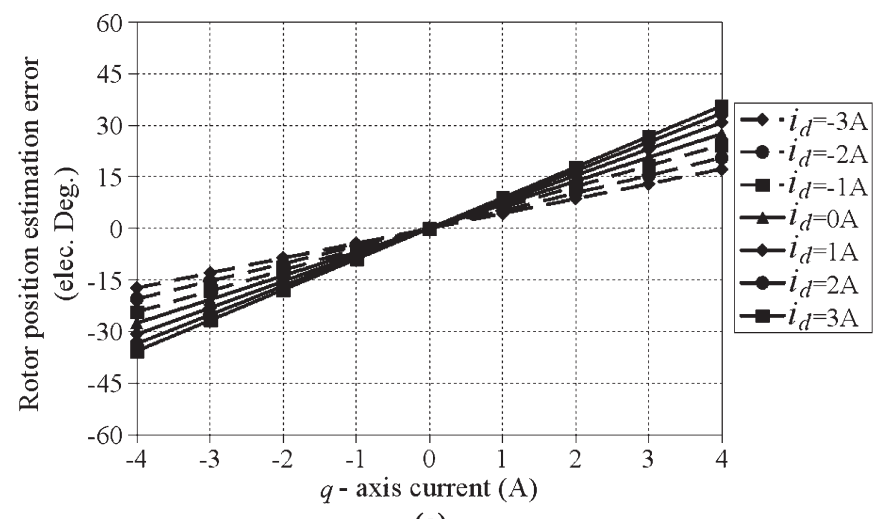

(a)

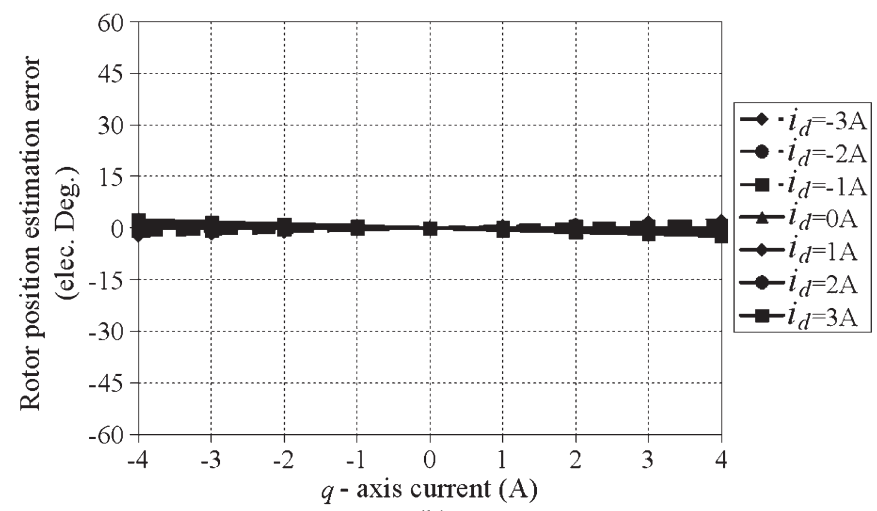

(b)

Fig. 8. Simulated rotor-position-estimation error. (a) Conventional method, $\operatorname{MAX}\left(\theta_{r}^{e}-\theta_{r}\right)=37.4^{\circ}$. (b) Improved method, $\operatorname{MAX}\left(\theta_{r}^{e}-\theta_{r}\right)=2.7^{\circ}$. 
determine the cross-coupling factor directly for subsequent use in the proposed sensorless-control scheme. Both measurements and simulations show that a significant improvement in the accuracy of the rotor-position estimation can be achieved, in both dynamic and steady-state modes of operation, compared with the conventional signal-injection sensorless method.

\section{REFERENCES}

[1] K. R. Shouse and D. G. Taylor, "Sensorless velocity control of permanentmagnet synchronous motors," IEEE Trans. Control Syst. Technol., vol. 6 , no. 3, pp. 313-324, May 1998.

[2] S. Morimoto, K. Kawamoto, M. Sanada, and Y. Takeda, "Sensorless control strategy for salient-pole PMSM based on extended EMF in rotating reference frame," IEEE Trans. Ind. Appl., vol. 38, no. 4, pp. 1054-1061, Jul./Aug. 2002.

[3] Z. Chen, M. Tomita, S. Koki, and S. Okuma, "An extended electromotive force model for sensorless control of interior permanent-magnet synchronous motors," IEEE Trans. Ind. Electron., vol. 50, no. 2, pp. 288-295, Apr. 2003.

[4] S. Ogasawara and H. Akagi, "Implementation and position control performance of a position-sensorless IPM motor drive system based on magnetic saliency," IEEE Trans. Ind. Appl., vol. 34, no. 4, pp. 806-812, Jul./Aug. 1998.

[5] M. J. Corley and R. D. Lorenz, "Rotor position and velocity estimation for a salient-pole permanent magnet synchronous machine at standstill and high speed," IEEE Trans. Ind. Appl., vol. 34, no. 4, pp. 784-789, Jul./Aug. 1998.

[6] T. Aihara, A. Toba, T. Yanase, A. Mashimo, and K. Endo, "Sensorless torque control of salient-pole synchronous motor at zero-speed operation," IEEE Trans. Power Electron., vol. 14, no. 1, pp. 202-208, Jan. 1999.

[7] J. I. Ha, K. Ide, T. Sawa, and S. K. Sul, "Sensorless rotor position estimation of an interior permanent-magnet motor from initial states," IEEE Trans. Ind. Appl., vol. 39, no. 3, pp. 761-767, May/Jun. 2003.

[8] H. Kim, K. K. Huh, and R. D. Lorenz, "A novel method for initial rotor position estimation for IPM synchronous machine drives," IEEE Trans. Ind. Appl., vol. 40, no. 5, pp. 1369-1378, Sep./Oct. 2004.

[9] J. H. Jang, S. K. Sul, J. I. Ha, K. Ide, and M. Sawamura, "Sensorless drive of surface-mounted permanent-magnet motor by high-frequency signal injection based on magnetic saliency," IEEE Trans. Ind. Appl., vol. 39, no. 4, pp. 1031-1039, Jul./Aug. 2003.

[10] C. Silva, G. M. Asher, M. Sumner, and K. J. Bradley, "Sensorless rotor position control in a surface mounted PM machine using HF voltage injection," in Proc. IEEE EPE-PEMC, Dubrovnik, Croatia, 2002.

[11] C. Silva, G. M. Asher, and M. Sumner, "Hybrid rotor position observer for wide speed-range sensorless PM motor drives including zero speed," IEEE Trans. Ind. Electron., vol. 53, no. 2, pp. 373-378, Apr. 2006.

[12] P. Guglielmi, M. Pastorelli, and A. Vagati, "Cross saturation effects in IPM motors and related impact on zero-speed sensorless control," in Conf. Rec. IEEE IAS Annu. Meeting, 2005, vol. 4, pp. 2546-2552.

[13] N. Bianchi and S. Bolognani, "Influence of rotor geometry of an interior PM motor on sensorless control feasibility," in Conf. Rec. IEEE IAS Annu. Meeting, 2005, vol. 4, pp. 2553-2560.

[14] B. Stumberger, G. Stumberger, D. Dolinar, A. Hamler, and M. Trlep, "Evaluation of saturation and cross-magnetization effects in interior permanent-magnet synchronous motor," IEEE Trans. Ind. Appl., vol. 39, no. 5, pp. 1264-1271, Sep./Oct. 2003.

[15] A. E. Fitzgerald, C. Kingsley, Jr., and S. D. Umans, Electric Machinery, 5th ed. New York: McGraw-Hill, 1992.

[16] Y. S. Chen, Z. Q. Zhu, and D. Howe, "Calculation of $d$ - and $q$-axis inductances of PM brushless AC machines accounting for skew," IEEE Trans. Magn., vol. 41, no. 10, pp. 3940-3942, Oct. 2005.

[17] S. Morimoto, M. Sanada, and Y. Takeda, "Inverter-driven synchronous motors for constant power," IEEE Trans. Ind. Appl., vol. 2, no. 6, pp. 18-24, Nov./Dec. 1996

[18] J. M. Kim and S. K. Sul, "Speed control of interior permanent magnet synchronous motor drive for the flux weakening operation," IEEE Trans. Ind. Appl., vol. 33, no. 1, pp. 43-48, Jan./Feb. 1997.

[19] Z. Q. Zhu, Y. Li, D. Howe, and C. M. Bingham, "Compensation for rotor position estimation error due to cross-coupling magnetic saturation in signal injection based sensorless control of PM brushless AC motors," in Proc. Int. Elect. Mach. Drives Conf., Antalya, Turkey, May 3-5, 2007, pp. 208-213.

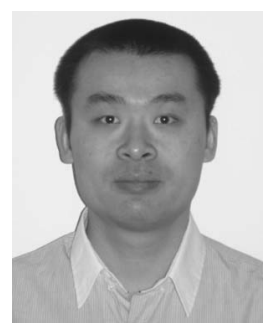

Yi Li was born in Anhui Province, China, in 1977. $\mathrm{He}$ received the B.Eng. and M.Eng. degrees from the Department of Automation, Tsinghua University, Beijing, China, in 1999 and 2002, respectively. Since 2004, he has been working toward the Ph.D. degree at the University of Sheffield, Sheffield, U.K.

$\mathrm{He}$ is currently also a Senior Engineer with Protean Electric Ltd., U.K. His research interests are sensorless control, power electronics, and machine modeling of permanent-magnet brushless ac motors.

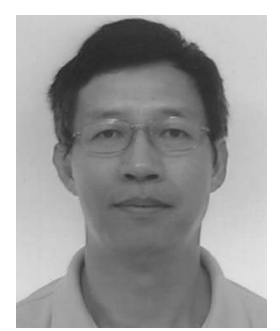

Z. Q. Zhu (M'90-SM'00-F'09) received the B.Eng. and M.Sc. degrees in electrical and electronic engineering from Zhejiang University, Hangzhou, China, in 1982 and 1984, respectively, and the Ph.D. degree in electrical and electronic engineering from the University of Sheffield, Sheffield, U.K., in 1991.

From 1984 to 1988, he was a Lecturer in the Department of Electrical Engineering, Zhejiang University. Since 1988, he has been with the University of Sheffield, where he was initially a Research Associate and was subsequently appointed to an established post as a Senior Research Officer/Senior Research Scientist. Since 2000, he has been a Professor of Electrical Machines and Control Systems in the Department of Electronic and Electrical Engineering, University of Sheffield, and is currently Head of the Electrical Machines and Drives Research Group. His current major research interests include design and control of permanent-magnet brushless machines and drives, for applications ranging from automotive and aerospace to renewable energy.

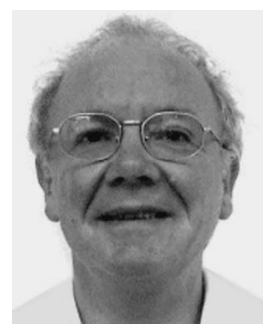

David Howe received the B.Tech and M.Sc. degrees in electrical power engineering from the University of Bradford, Bradford, U.K., in 1966 and 1967, respectively, and the Ph.D. degree in electrical power engineering from the University of Southampton, Southampton, U.K., in 1974

He has held academic posts at Brunel and Southampton Universities and spent a period in industry with NEI Parsons Ltd., working on electromagnetic problems related to turbogenerators. He is currently an Emeritus Professor in the Department of Electronic and Electrical Engineering, University of Sheffield. His research activities span all facets of controlled electrical-drive systems, with particular emphasis on permanent-magnet excited machines.

Prof. Howe is a Fellow of the Royal Academy of Engineering and Fellow of the Institution of Electrical Engineers, U.K. 


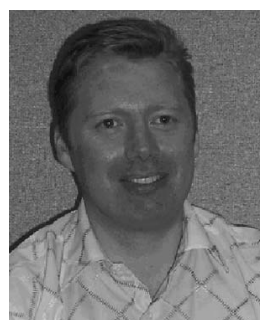

Chris M. Bingham (M'00) received the B.Eng. degree in electronic systems and control engineering from Sheffield City Polytechnic, Sheffield, U.K., in 1989, the M.Sc.(Eng) degree in control systems engineering from the University of Sheffield, Sheffield,

U.K., in 1990, and the Ph.D. degree from Cranfield University, Cranfield, U.K., in 1994, for research on control systems to accommodate nonlinear dynamic effects in aerospace flight-surface actuators

Following a period of post-doctoral research at Cranfield University, he took up a Research Associate position at the University of Sheffield, where since 2004, he has been a Senior Lecturer in the Department of Electronic and Electrical Engineering. His research interests include modeling, control, energy management, and state monitoring of power electronics and drive systems for industrial and domestic products.

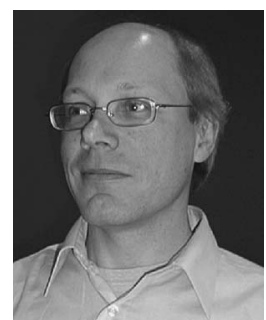

Dave A. Stone received the B.Eng. degree in electronic engineering from the University of Sheffield, Sheffield, U.K., in 1984, and the Ph.D. degree from Liverpool University, Liverpool, U.K., in 1989.

After completing the Ph.D. degree, he joined the University of Sheffield as a member of the academic staff, specializing in power electronics and machinedrive systems. He is currently a Senior Lecturer. His current research interests are in resonant power converters, hybrid electric vehicles, battery state-ofcharge and state-of-health monitoring, electromagnetic compatibility, and novel lamp ballasts for low-pressure fluorescent lamps. 